\title{
Synergistic Inhibitory Activity of Bacillomycin D, Surfactin and Nisin against Thermoascus crustaceus, Neosartorya hiratsukae and Bacillus subtilis, Responsible for Cardboard Spoilage
}

\author{
Uttara Vairagkar ${ }^{1,2}$, Rutuja Ankulkar ${ }^{1}$, Zafar Ahmed $^{1}$ and Yasmin Mirza ${ }^{1 *}$ (D) \\ ${ }^{1}$ Praj-Matrix - R\&D Centre (Division of Praj Industries Limited), 402/403/1098, Urawade, Pirangut, Mulshi, \\ Pune - 412 115, Maharashtra, India. \\ ${ }^{2}$ Department of Technology, Savitribai Phule Pune University, Ganeshkhind, Pune - 411 007, Maharashtra, \\ India.
}

\begin{abstract}
Corrugated cardboard boxes are one of the largest paper-based packaging forms used for shipping and handling of wide variety of products in different end-use industries due to low cost, low weight and recyclability. Due to its organic composition, they are highly susceptible to spoilage from heat-resistant microbial spores, leading to economic losses and health risks. In this study, the efficacy of lipopeptides produced from Bacillus amyloliquefaciens MTCC 10456 against thermotolerant Thermoascus crustaceus, Neosartorya hiratsukae and Bacillus subtilis, isolated from spoiled cardboard boxes, was investigated. Lipopeptides were isolated by salt-precipitation of fermentation broth and activity-guided Reverse Phase-High Performance Liquid Chromatography (RP-HPLC). Inhibitory fractions consisted of bacillomycin $D$ and surfactin, which were identified using liquid chromatography-electrospray ionization mass spectrometry (LC-ESI-MS/MS) analysis. Mixture of lipopeptides with nisin (3:2 w/w) asserted significant synergistic effect on the tested pathogens which reduced the minimum inhibitory concentrations (MIC) values and increased their inhibition spectra. Preservative coating containing lipopeptides and nisin was applied on the corrugated cardboard surfaces by mixing with starch-based additive by spread-coating method. It demonstrated biopreservative efficacy against the targeted microorganisms at during the observational period of $\mathbf{1 8 0}$ days. Reduction in microbial count of 4 log cycles was observed in $\mathbf{2 0}$ days and showed controlled release of coated peptides which indicate its suitability for packaging purposes. Findings from this study suggests an effective and scalable strategy to prevent microbial spoilage thereby extending the storage period of cardboard boxes.
\end{abstract}

Keywords: Bacillus amyloliquefaciens, thermotolerant microorganisms, preservative coating, lipopeptides, corrugated cardboard boxes 2020;14(4):2555-2567. doi: 10.22207/JPAM.14.4.31

(C) The Author(s) 2020. Open Access. This article is distributed under the terms of the Creative Commons Attribution 4.0 International License which permits unrestricted use, sharing, distribution, and reproduction in any medium, provided you give appropriate credit to the original author(s) and the source, provide a link to the Creative Commons license, and indicate if changes were made. 


\section{INTRODUCTION}

Corrugated cardboard boxes are one of the most widely used secondary packaging materials due to their flexibility, low weight, low cost and environmental-friendly nature. Corrugated cardboard packaging is a sub-segment of the paper packaging market which accounts for $44 \%$ of the total market and was estimated at USD 69.91 billion in $2019^{1}$. The demand for corrugated boxes is continually witnessing substantial growth (more than 4\%) due to the increasing demand from retail e-commerce packaging industry. The major challenges faced by this market are environmental concerns due to desertification, toxins production, microbial spoilage of paper and machinery leading to huge losses ${ }^{1}$.

Paper-based packaging material is reused and recycled more than any other packaging materials such as metals and plastics, which makes it an economically viable and sustainable choice ${ }^{2}$. In paper-making process, starch or cellulose is the most common cost-effective additive, which also imparts mechanical strength and good barrier properties. However, the starch and cellulose derivatives show sensitivity to microbial attack. At suitable temperature $\left(30-45^{\circ} \mathrm{C}\right)$ and $\mathrm{pH}(4-10)$ conditions during paper manufacturing process, it provides an ideal environment for the growth of microorganisms. Extreme temperatures during the paper drying process kill most of the contaminants but heat-resistant spores of bacteria and fungi, which leads to smell, discoloration, irregularity and overall decrease in display quality of the paper ${ }^{3}$. The thermotolerant spoilage microorganisms present on the cardboard surface can penetrate and damage the packaged goods and may cause health hazards to the consumers. Thus, in response to the increasing demand for safe and high-quality goods, it is necessary to develop new bio-based or naturally derived antimicrobial coating material without disturbing the barrier and strength properties for packaging paper ${ }^{4}$.

Members of Bacillus species are known to produce diverse molecules including secondary metabolites which exhibit a wide spectrum of antimicrobial activities such as bacteriocins, lipopeptides, polyketides and peptide antibiotics. Due to antimicrobial action of lipopeptides, they have potential for agricultural, pharmaceutical and environmental applications $s^{5}$. Bacillus spp. form resistant spores due to which they are ubiquitous in nature, exhibit high thermal tolerance and have shorter growth rates, and are thus considered to be good candidates as biological control agents. There is a growing interest in the commercialization of these bacteria-derived metabolites because of their biodegradability, availability and low toxicity, which are desirable factors for their potential applications in the industry ${ }^{6,7}$. Thus, antagonistic metabolites produced from Bacillus spp. can be considered as an alternative to existing antimicrobial agents used for preservation of paper-based packaging material. The use of such natural antimicrobial agents could be an efficient method in antimicrobial packaging, as they present lower risk to the consumers as compared to the synthetic antimicrobial agents and can be made available throughout the year ${ }^{4,8,9}$.

In this research work, the susceptibility of thermotolerant microorganisms, isolated from spoiled corrugated cardboard boxes to the lipopeptides from seaweed-associated $B$. amyloliquefaciens MTCC 10456 was evaluated. This is the first study to suggest that lipopeptides produced by B. amyloliquefaciens MTCC 10456 in combination with nisin, can be considered as potential candidates for the development of preservative coating for cardboard-based packaging systems for prolonged storage.

\section{MATERIALS AND METHODS}

\section{Identification of cardboard spoilage microflora}

The corrugated cardboard boxes used for this study were procured from "Parksons packaging Ltd, Pune, India". Microbial contamination of the cardboard boxes was estimated by international standard method based on agar flooding method ${ }^{10}$. $10 \times 10 \mathrm{~mm}$ of cardboard samples were placed in $10 \mathrm{~cm}$ Petri dishes and molten Potato Dextrose agar (PDA, Himedia, Mumbai, India) was poured over it. Incubation was carried out for 7 days at $27^{\circ} \mathrm{C}$. The individual bacterial and fungal colonies were counted and spread on NA and PDA plates, respectively, to obtain pure cultures. Each of the isolated bacterial and fungal colony was identified and characterized by $16 \mathrm{~S}$ rDNA gene sequence analysis. 


\section{Fermentative production and extraction of lipopeptides}

Bacillus amyloliquefaciens strain MTCC 10456 was procured from 'Microbial Type Culture Collection and Gene Bank' (MTCC), Chandigarh, India. It was preserved as stock culture in $20 \%$ $(v / v)$ glycerol at $-80^{\circ} \mathrm{C}$ after growing in Nutrient Broth (NB, Himedia, India) at $37^{\circ} \mathrm{C}$ for $24 \mathrm{~h}$. The seed culture of $B$. amyloliquefaciens MTCC 10456 was initiated in $100 \mathrm{~mL}$ Tryptone soya broth (Himedia, Mumbai, India) at $37^{\circ} \mathrm{C}$ at $150 \mathrm{rpm}$ for $18 \mathrm{~h}$ as seed culture. It was then inoculated into $900 \mathrm{~mL}$ of Tryptone soya broth and fermentation was carried out at $30^{\circ} \mathrm{C}$ for $72 \mathrm{~h}$ with shaking at $150 \mathrm{rpm}$. Centrifugation was carried out at $7000 \mathrm{rpm}$ for $20 \mathrm{~min}$ to remove the biomass and the $\mathrm{pH}$ of the supernatant was set at 8.5. It was then gently added with ammonium sulphate $\left(\left(\mathrm{NH}_{4}\right)_{2} \mathrm{SO}_{4}\right)$ powder to achieve saturation level of $60 \%$ with continuous stirring to dissolve the salt completely and stored at $4-8^{\circ} \mathrm{C}$ for $12-14$ h. Precipitated proteins were the collected by centrifugation at $8000 \mathrm{rpm}$ for $20 \mathrm{~min}$. The salt precipitated protein fraction was then desalted by passing through PD-10 desalting column (GE Healthcare, Chicago, United States) filled with 8.3 $\mathrm{mL}$ of Sephadex $\mathrm{G}-25$ resin and eluted in $100 \mathrm{mM}$ sodium phosphate buffer ( $\mathrm{pH}$ 7.4). The desalted fraction was designated as "LP extract or LPE" and freeze-dried for storage.

\section{Separation and identification of lipopeptides by} mass spectrometry

Identification of lipopeptides present in the LPE was done by Reverse Phase-Highperformance liquid chromatography (RP-HPLC) using an HPLC system (1200 series, Agilent, Santa Clara, United States). $10 \mathrm{mg}$ of LPE was injected into the column (C18 Eclipse plus, $4.6 \mathrm{~mm}$ internal diameter $\times 150 \mathrm{~mm}$ length and particle size $5 \mu \mathrm{m}$ ) from Agilent, Santa Clara, United States. A gradient solvent system of $0.1 \%$ trifluoroacetic acid (SigmaAldrich, St. Louis, United States) in water: A and $0.1 \%$ trifluoroacetic acid in acetonitrile: B (SigmaAldrich, St. Louis, United States) was used for the program: 0 to $20 \mathrm{~min}: 0-40 \% \mathrm{~B}, 20-30 \mathrm{~min}: 40$ to $80 \% \mathrm{~B}, 30$ to $35 \mathrm{~min}: 80$ to $100 \% \mathrm{~B}, 35$ to $45 \mathrm{~min}$ : 100 to $0 \% \mathrm{~B}$ at a flow rate of $1.0 \mathrm{~mL} \mathrm{~min}{ }^{-1}$ at $30^{\circ} \mathrm{C}$. The elution profile was observed at $220 \mathrm{~nm}$ and the individual fractions were freeze-dried and tested for antimicrobial activity at the concentration of $10 \mathrm{mg} \mathrm{mL}^{-1}$.

For the identification of lipopeptides, LC-ESI-MS/MS analysis was performed using a Phenomenex ECC 18 column of $4.6 \mathrm{~mm}$ internal diameter $\times 250 \mathrm{~mm}$ length $\times 5 \mu \mathrm{m}$ particle size) in TOF/Q-TOF Mass Spectrometer (G6550B, Agilent technologies, Santa Clara, United States). The capillary voltage was set as $4000 \mathrm{~V}$ with dry gas flow at $11 \mathrm{I} \mathrm{min}^{-1}$ and temperature of $290^{\circ} \mathrm{C}$. Each peak was measured in positive-ion mode and the masses of the individual peaks were screened in the $\mathrm{m} / \mathrm{z}$ range of $200-2000$. The lipopeptides were identified by matching with the exact calculated monoisotopic masses, adducts and their mass fragmentation patterns, according to previously published literature.

\section{In-vitro susceptibility test}

Susceptibility of spoilage microorganisms isolated from cardboard to LPE was evaluated by agar well diffusion method as per Ayed et al. $(2015)^{11}$, with some modifications. NA and PDA were used for the growth of bacterial and fungal strains, respectively. Bacterial and fungal strains were diluted to $10^{6} \mathrm{CFU} \mathrm{mL}^{-1}$ and $5 \times 10^{4}$ spores $\mathrm{mL}^{-1}$, respectively using a haemocytometer. Each bacterial culture was added to molten nutrient agar cooled to $40^{\circ} \mathrm{C}$ and poured into petri dishes and $100 \mu \mathrm{L}$ of fungal spores were spread on the PDA plates. Wells (6 $\mathrm{mm}$ diameter) were prepared and $50 \mu \mathrm{L}$ of the test sample was added to them. The plates were then incubated for $24 \mathrm{~h}$ at $37^{\circ} \mathrm{C}$ for bacteria and for $48 \mathrm{~h}$ at $30^{\circ} \mathrm{C}$ for fungal strains. The radius of the zones of inhibition was recorded in millimetres. Arbitrary activity was determined against Thermoascus crustaceus CRS-15 and E. coli ATCC 35218. It was defined as the reciprocal of the highest dilution that formed a clear zone of inhibition and expressed as activity units (AU) per $\mathrm{mL}^{12}$.

\section{Determination of minimum inhibitory} concentration (MIC) of lipopeptides

The MIC of lipopeptides was calculated by using microdilution technique in 96-well microtiter plates (Thermo fisher scientific, Waltham, United States). The turbidity of the tested bacterial and fungal suspensions was adjusted to approximately $10^{6} \mathrm{CFU} \mathrm{mL}^{-1}$ by comparing with $0.5 \mathrm{McF}$ arland standard. Muller-Hinton Broth (MHB) (Himedia, 
Mumbai, India) was used for bacterial strains or Sabouraud Dextrose Broth (SDB) was used for fungal strains for dilution of inocula to $10^{3} \mathrm{CFU}$ $\mathrm{mL}^{-1}$. Initially, $100 \mu \mathrm{L}$ of SDB or MHB was added in all of the plate wells. $100 \mu \mathrm{L}$ of test solution was added to the first well and serially diluted to the next well to obtain samples of test concentrations from $8.625 \mathrm{mg} \mathrm{mL}^{-1}$ to $0.00042 \mathrm{mg} \mathrm{mL}^{-1} .100 \mu \mathrm{L}$ of each inoculum suspension was added to the wells except for sterility control. $200 \mu \mathrm{L}$ of MHB or SDB medium was added to sterility control and $100 \mu \mathrm{L}$ of MHB or SDB and $100 \mu \mathrm{L}$ of inoculum suspension was added to microbial growth control. As positive controls, standard antibiotic such as Azithromycin (Sigma-Aldrich, St. Louis, United States) and antifungal Ketoconazole (Sigma-Aldrich, St. Louis, United States) were used from $32 \mu \mathrm{g} \mathrm{mL}^{-1}$ to 0.0156 $\mu \mathrm{g} \mathrm{mL} \mathrm{L}^{-1}$. Incubation was carried out at $37^{\circ} \mathrm{C}$ for bacteria and $25^{\circ} \mathrm{C}$ for fungi, and the results were observed after 2 days. The lowest concentration of the test samples that inhibited bacterial and fungal growth was measured as the $\mathrm{MIC}^{13}$. The experiment was conducted in triplicate against tested strains.

Fractional inhibitory concentration (FIC) index of lipopeptides with nisin and pediocin

The checkerboard technique was used to determine the combined antimicrobial activity of the LPE with 'Nisin' produced from Lactococcus lactis (LPE+Nisin) and 'Pediocin' from Pediococcus pentosaceus (LPE+Pediocin) using by calculating the FIC index ${ }^{13} .100 \mu \mathrm{L}$ of MHB was distributed to each of the plate wells. $50 \mu \mathrm{L}$ of both test samples at their MIC concentrations and two concentrations higher and lower than MIC were added horizontally and vertically. $10 \mu \mathrm{L}$ of each of the inoculum suspensions were adjusted to $10^{3}$ CFU mL ${ }^{-1}$ were added to the wells. Controls were same as MIC test. Incubation was carried out at $37^{\circ} \mathrm{C}$ for bacteria and $25^{\circ} \mathrm{C}$ for fungi, and the results were recorded visually. The fractional inhibitory concentration index (FIC) was determined as:

$\mathrm{FIC}_{1}=\left(\mathrm{MIC}_{1}\right.$ combined $/ \mathrm{MIC}_{1}$ alone $), \mathrm{FIC}_{2}=\left(\mathrm{MIC}_{2}\right.$ combined / $\mathrm{MIC}_{2}$ alone) $\mathrm{FIC}=\mathrm{FIC}_{1}+\mathrm{FIC}_{2}$

The results were interpreted as: $\mathrm{FIC} \leq$ 0.5 : synergistic activity (S), $0.5<\mathrm{FIC} \leq 1$ : additive activity (AD), $1<$ FIC $\leq 4$ : no interaction (I) and FIC $>4$ : antagonistic activity was observed.

\section{Stability study}

To determine the thermal stability of LPE, it was exposed to temperatures ranging from $4-120^{\circ} \mathrm{C}$ for $30 \mathrm{~s}$ to $30 \mathrm{~min}$ and cooled to room temperature. The $\mathrm{pH}$ of LPE was varied from 2 to 12 by using $0.5 \mathrm{M}$ of $\mathrm{HCl}$ and $0.5 \mathrm{M}$ of $\mathrm{NaOH}$ solution and incubating it at room temperature for $1 \mathrm{hr}$. The residual antimicrobial activity of treated LPE was tested against the indicator strains. Untreated LPE samples were taken as controls. The residual activity at each data point was recorded in triplicate.

\section{Application of lipopeptides and nisin for cardboard preservation}

Cardboard-based packaging material was constructed of three separate layers: an outside fibreboard liner, an inside fibreboard liner and a middle-corrugated medium (fluting) secured together by starch as binding agent. Cardboard samples of dimension $5 \mathrm{~cm} \times 5 \mathrm{~cm}$ were cut from the cardboard box and placed into bottom portion of the sterile petri dishes. Starch based glue was heated to $80^{\circ} \mathrm{C}$ and LPE+Nisin was dissolved in it to the final concentrations of $1 \%$ and $2 \%(w / w)$ to obtain a homogenous mixture. Starch based glue was allowed to cool to $40^{\circ} \mathrm{C}$ and microbial load $\left(10^{6} \mathrm{CFU} \mathrm{mL} \mathrm{m}^{-1}\right)$ of isolates obtained from spoiled cardboard was added to it. The viscous paste formed was spread-coated between the fibreboard liners and corrugated medium for the assembly of corrugated cardboard sheets. Positive control was prepared by addition of commercially used salicylic acid $(1 \% \mathrm{w} / \mathrm{w})$ in the starch-based glue and in negative control, only microbial load was added. Plates were incubated at $25^{\circ} \mathrm{C}, 37^{\circ} \mathrm{C}$ and $55^{\circ} \mathrm{C}$ at $50 \pm 5 \%$ r.h. and examined after every 5 days till microbial growth appeared. The efficacy of LPE+Nisin to prevent microbial spoilage was evaluated by visual observation, estimation of total microbial count and inhibitory activity assays of the treated cardboard surfaces at $25^{\circ} \mathrm{C}$.

Estimation of total microbial count, adsorption and release rates

The total microbial count on the tested cardboard samples was estimated by counting the bacterial and fungal colonies by placing the 10 $\mathrm{mm} \times 10 \mathrm{~mm}$ sample from the treated cardboards on the NA and PDA plates after every 5 days of incubation. The ability of the LPE+Nisin to 
disperse throughout the coating was assessed by determining their adsorption and release rate from the cardboard surface as per method followed by Mauriello et al., (2005) ${ }^{14}$. The treated cardboard samples were removed after spread-coating step, after 2, 4, 6, 8, 10, 20 and 30 min and placed on NA plates seeded with E. coli ATCC 35218 and PDA plates seeded with $T$. crustaceus CRS-15. Based on the inhibition zones around the indicator strains, the adsorption rate was measured. For release rate, $10 \mathrm{~mm} \times 10 \mathrm{~mm}$ pieces of the treated cardboards were placed in sterile distilled water and removed at 30, 60, 90 and 120 min and tested for antimicrobial activity.

\section{Factory trial}

The efficiency of LPE+Nisin for the preservation of cardboard-based packaging material was evaluated at "Parksons packaging Ltd, Pune. Starch-based glue was heated to $80-100^{\circ} \mathrm{C}$ and mixed with LPE+Nisin at the concentration of $1 \%, 0.6 \%$ and $0.4 \%(w / w)$ for $30 \mathrm{~min}$. LPE+Nisin at each concentration was placed in a tray and spreadcoated between inner fibreboard and corrugated sheet by passing through roller machine to prepare 100 boxes. In total, 300 cardboard boxes of 0.65 $\mathrm{m}^{2}$ area were prepared and the final concentration of LPE+Nisin was calculated to be $800 \mathrm{mg} \mathrm{m}^{-2}$, $527.27 \mathrm{mg} \mathrm{m}^{-2}$ and $335.24 \mathrm{mg} \mathrm{m}^{-2}$ in each trial. All the boxes were kept at the storage facility at room temperature $\left(20-25^{\circ} \mathrm{C}, 50 \pm 5 \%\right.$ r.h. $)$. The efficacy of LPE+Nisin coating was evaluated by examining individual boxes after every 5 days over a period of 180 days by visual observation, estimation of total microbial count and inhibitory activity assays.

\section{RESULTS AND DISCUSSION}

Identification of cardboard spoilage microflora

In this study, 16S rDNA genes from the isolated bacterial and fungal strains from the spoiled cardboard samples were amplified by PCR and compared against the GenBank database by BLAST analysis. Based on the phylogenetic analysis, isolate CRS-15, CRS-16 and CRS-17 were identified as Thermoascus crustaceus, Neosartorya hiratsukae and Bacillus subtilis, respectively (Fig. 1). Thermoascus crustaceus, is a thermophilic fungus which can cause peritonitis or pulmonary infections in immunocompromised patients and has high rates of morbidity and mortality ${ }^{15-17}$. Neosartorya hiratsukae, a close relative of Aspergillus fumigatus, is also a thermophilic fungus which is known to cause opportunistic infections such as cerebral aspergillosis, peritonitis and rhinosinusitis ${ }^{18-20}$. Bacillus spp. are capable of forming biofilms and thermoresistant spores and are most commonly found bacteria in the paper products $^{3}$.

Inhibitory activity of lipopeptides against cardboard spoilage microorganisms

Inhibitory activity assays demonstrated

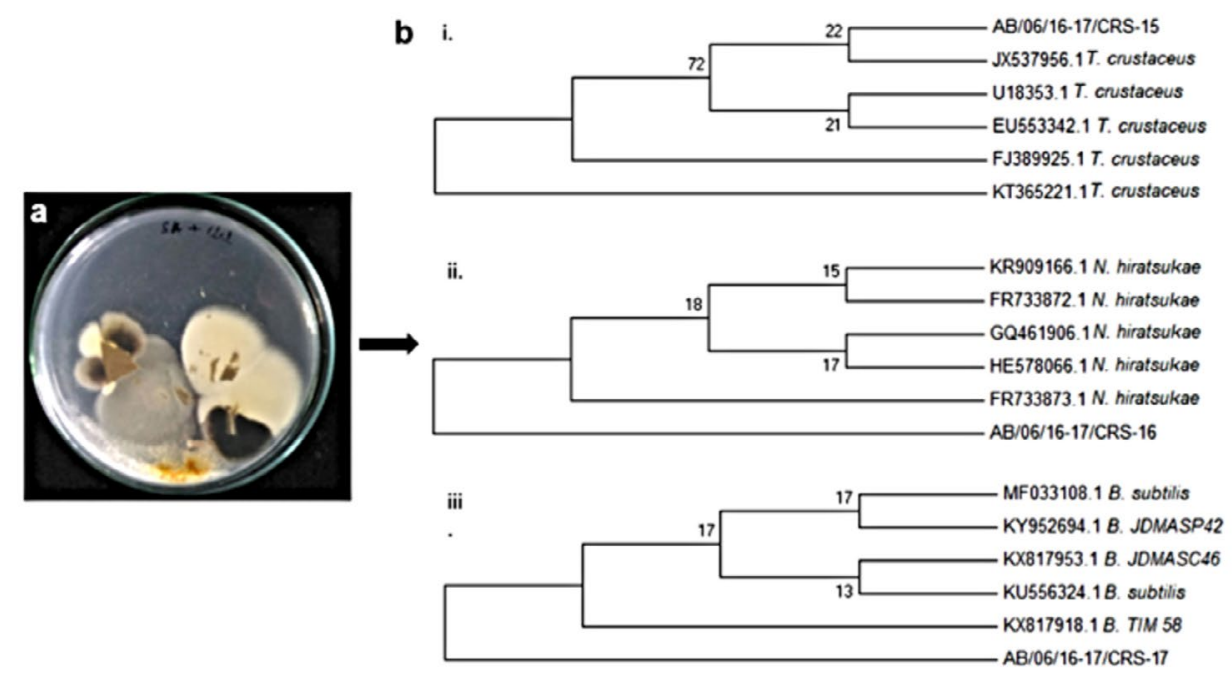

Fig. 1. Isolation of spoilage microorganism from cardboard using agar flooding method b. Phylogenetic tree of 16S rDNA gene sequences of i. T. crustaceus CRS-15 ii. N.hiratsukae CRS-16 iii. B. subtilis CRS-17 
that all the three strains isolated from cardboard were susceptible to LPE from Bacillus amyloliquefaciens MTCC 10456. Clear zones of inhibition of radii $7 \pm 0.56,8 \pm 0.34$ and $8 \pm 0.82 \mathrm{~mm}$ were observed against Thermoascus crustaceus CRS-15, Neosartorya hiratsukae CRS-16 and Bacillus subtilis CRS-17, respectively (Fig. 2). 0.1 $M$ sodium phosphate buffer $(\mathrm{pH} 7.4)$ was tested as negative control, did not show any inhibitory activity.

The worldwide need for packaged products such as food, medicines, chemicals and household appliances are increasing due to rapid urbanization. Paper-based cardboard boxes are one of the most widely used materials due to their flexibility, low weight, low cost, biodegradability, recyclability and environmental-friendly nature. Paper production or recycling takes place in an open unsterile environment and due to its natural composition, long-term storage conditions and transportation, there is a great risk of microbial spoilage, particularly from heat-resistant spores of bacteria and fungi, that causes decreased product quality, contaminated machinery and subsequent disease outbreaks ${ }^{2}$. Antibacterial agents such as organic acids, bacteriocins, enzymes, chitosan, plant extracts and antifungals such as sorbates, salicylic acid, glutaraldehyde and formaldehyde have been extensively tested in antimicrobial packaging systems. However, their usage is restricted due to narrow target specificity, low stability, environmental toxicity and development of resistance against pathogenic strains ${ }^{4,8,9}$. Thus, screening and identification of alternate antimicrobial agents, which can replace or be used in combination with existing compounds for preservation of paper-based packaging material against such thermotolerant spoilage microbes is necessary.

In the last few years, natural products such as bacteriocins and antimicrobial peptides produced by bacteria have gained attention

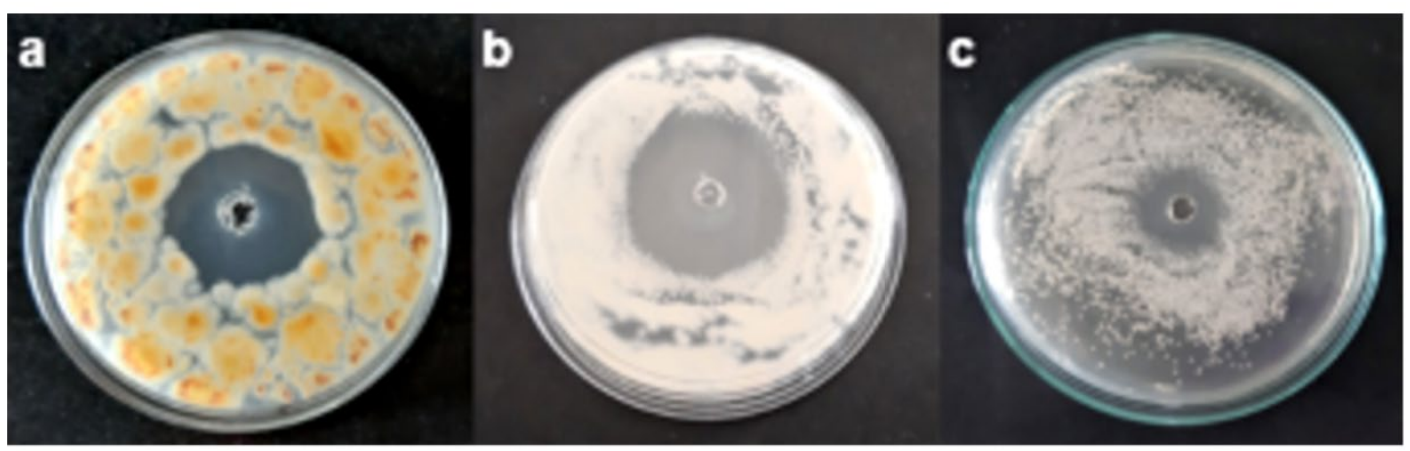

Fig. 2. Antimicrobial activity of lipopeptides extract (LPE) for B. amyloliquefaciens MTCC 10456 by agar well diffusion asssay showing clear zone of inhibition against a T.crustaceus CRS-15 b. N.hiratsukae CRS-16 c. B.subtilis CRS-17

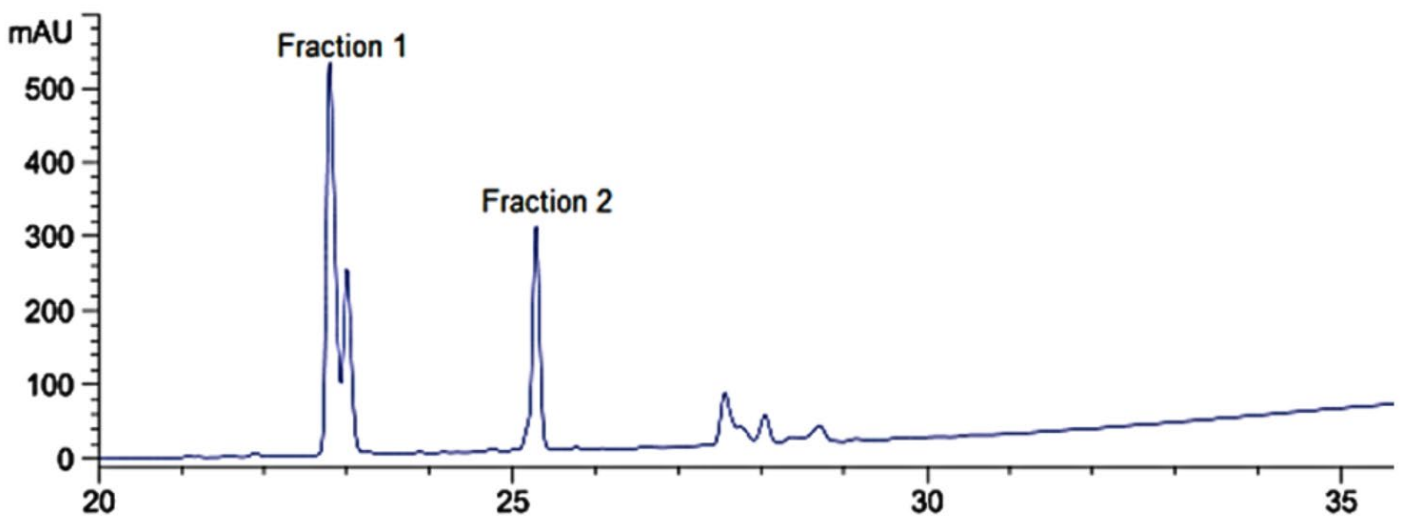

Fig. 3. RP-HPLC chromatogram of lipopetides extract (LPE) from B. amyloliquefaciens MTCC 10456 
Vairagkar et al. | J Pure Appl Microbiol | 14(4):2555-2567 | December 2020 | https://doi.org/10.22207/JPAM.14.4.31

Table 1. Lipopeptides produced by B. amyloliquefaciens MTCC 10456 and detected by LC-ESI-MS/MS analysis

\begin{tabular}{|c|c|c|c|c|c|c|}
\hline $\begin{array}{l}\text { Fraction } \\
\text { number }\end{array}$ & $\begin{array}{c}\text { Retention } \\
\text { time (min) }\end{array}$ & $\mathrm{m} / \mathrm{z}$ & $\begin{array}{l}\text { Mass } \\
\text { peak }\end{array}$ & $\begin{array}{l}\text { Molecular } \\
\text { weight }\end{array}$ & $\begin{array}{c}\text { Possible } \\
\text { assignment }\end{array}$ & References \\
\hline 1 & 22.8 & $\begin{array}{l}1031.5 \\
1045.4\end{array}$ & {$[\mathrm{M}+\mathrm{H}]^{+}$} & $\begin{array}{l}1030 \\
1044\end{array}$ & $\begin{array}{l}\text { C14 Bacillomycin D, } \\
\text { C15 Bacillomycin D }\end{array}$ & 23 \\
\hline 2 & 25.2 & $\begin{array}{c}1030.63 \\
1044.65 \\
1058.6\end{array}$ & {$[\mathrm{M}+\mathrm{Na}]^{+}$} & $\begin{array}{l}1007 \\
1021 \\
1035\end{array}$ & $\begin{array}{l}\text { C13 Surfactin, } \\
\text { C14 Surfactin, } \\
\text { C15 Surfactin }\end{array}$ & 26 \\
\hline
\end{tabular}

for the bio-preservation of food products and packaging films. Members of marine Bacillus species represent the most promising strategy for addressing these issues as they are ubiquitously present in the environment and are considered as economically and ecologically valuable sources for the production of bioactive compounds as compared to any other sources ${ }^{21}$. Most of the studies regarding antimicrobial metabolites from Bacillus spp. have mentioned their application in food, agriculture, pharmaceutical or bioremediation, very few of them have done it in context of development of preservative coatings for paper-based packaging materials ${ }^{22}$. Thus, this work highlights the role of antagonistic metabolites from B. amyloliquefaciens MTCC
10456 as effective agents to inhibit thermotolerant bacteria and fungi, responsible for the spoilage of cardboard boxes and have inherent ability to cause human infections.

Identification of lipopeptides by mass spectrometry analysis

Lipopeptides produced from $B$. amyloliquefaciens MTCC 10456, isolated by salt-precipitation method were subjected to RPHPLC for further separation, two fractions were collected at the retention times of 22.8 and 25.2 minutes and labelled as Fraction 1 and Fraction 2, respectively (Fig. 3). Fraction 1 exhibited inhibitory activity against $T$. crustaceus CRS_15 as evidenced by clear of zone of inhibition of radius $7 \mathrm{~mm}$ and fraction 2 exhibited inhibitory activity against $E$.

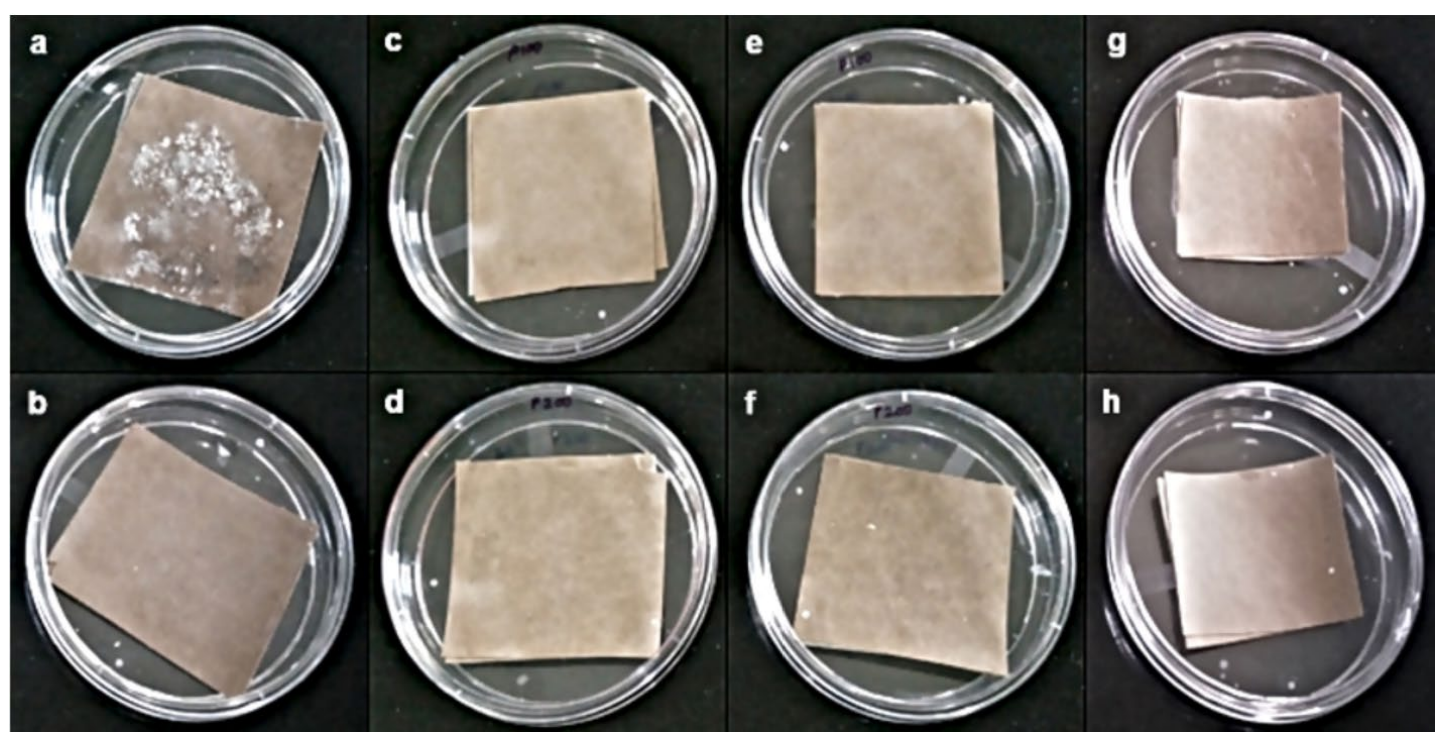

Fig. 4. Application of $L P E+N i s i n$ for cardboard preservation a. Corrugated cardboard with 'no inhibition' of microbial

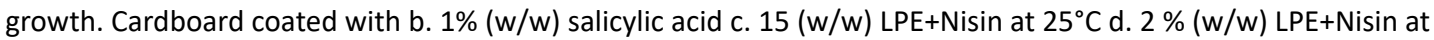

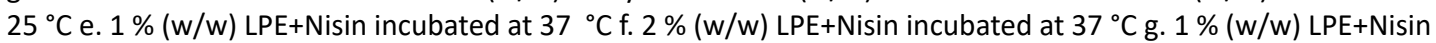
incubated at $55^{\circ} \mathrm{C} \mathrm{h} .2 \%(\mathrm{w} / \mathrm{w}) \mathrm{LPE}+$ Nisin incubated at $55^{\circ} \mathrm{C}$ observed after 180 days of incubation 
coli ATCC 35218 as well as T. crustaceus CRS-15, resulting in zone of inhibition of radii $8 \mathrm{~mm}$ and 2 $\mathrm{mm}$, respectively.

To determine the accurate molecular mass of the lipopeptides produced from $B$. amyloliquefaciens MTCC 10456, LC-ESI-MS/ MS analysis was carried out (Table 1). The mass spectrum of fraction 1 revealed a major peak at molecular mass of $1031.5[\mathrm{M}+\mathrm{H}]^{+}$corresponding to molecular weight of C14 bacillomycin D (1030) and a peak at molecular mass of 1045.4 $[\mathrm{M}+\mathrm{H}]^{+}$corresponding to molecular weight of C15 bacillomycin D (1044). The peak at m/z 1031 fragmented in to masses of 1014. 51, 997.49 (loss of $\mathrm{NH}_{3}$ in each peak) and 979.45 (neutral loss of $\mathrm{H}_{2} \mathrm{O}$ ). lon peaks at 510 corresponded to loss of $\mathrm{H}_{2} \mathrm{O}$ from Thr -Ser -Glu -Pro -Asn chain, 673 for loss of $\mathrm{H}_{2} \mathrm{O}$ (Thr -Ser - Glu -Pro -Asn -Tyr -Asn) and 805 (Thr -Ser -Glu - Pro -Asn -Tyr -Asn - $\beta$-amino fatty acid) and fragment ions at $\mathrm{m} / \mathrm{z} 617$ ( $\beta$-amino fatty acid-Asn -Tyr -Asn) and 948 ( $\beta$-amino fatty acidAsn -Tyr -Asn -Pro -Glu -Ser) were also observed, which confirmed the assignment of fraction 1 as C14 bacillomycin D consisting of -Asn -Tyr -Asn -Pro -Glu -Ser -Thr attached to $\beta$-amino fatty acid chain, which is a characteristic sequence for bacillomycin D family. Mass fragmentation of peak at $\mathrm{m} / \mathrm{z}$ 1045 showed fragment ions at $\mathrm{m} / \mathrm{z}$ of 1028.52 , 1011.52 with a loss of $\mathrm{NH}_{3}$ in each peak (mass difference of 17) and 993.49 with a neutral loss of $\mathrm{H}_{2} \mathrm{O}$ molecule (mass difference of 18 ). Thus, both the peaks exhibited similar fragment ions which confirmed their homologous nature but consisting of $\beta$-amino fatty acid with $\mathrm{C} 14$ and $\mathrm{C} 15$ chains, respectively (Supplementary data, Fig. S1 and S2). These results are in agreement with previous reports which demonstrated that bacillomycin $D$ could be produced by $B$. amyloliquefaciens strains and demonstrate strong antifungal activity ${ }^{23,24}$.

Table 2. Synergistic activity of lipopeptides extract (LPE) from B. amyloliquefaciens MTCC 10456 with nisin and pediocin against tested bacterial pathogens

\begin{tabular}{lcccccccc}
\hline \multirow{2}{*}{ Bacteria } & \multirow{2}{*}{ ATCC No. } & LPE & Nisin & Pediocin & \multicolumn{2}{c}{ LPE+Nisin } & \multicolumn{2}{c}{ LPE+Pediocin } \\
\cline { 3 - 8 } & & \multicolumn{3}{c}{$\mathrm{MIC}\left(\mathrm{mg} \mathrm{mL}^{-1}\right)$} & $\mathrm{FIC}^{2}$ & Activity & FIC & Activity \\
\hline S. aureus & 6538 & 4.31 & 4.25 & 10 & 0.51 & $\mathrm{~S}$ & 3.32 & $\mathrm{I}$ \\
E. coli & 35218 & 4.31 & 25 & 50 & 0.35 & $\mathrm{~S}$ & 2 & $\mathrm{I}$ \\
S. enterica & 12011 & 4.31 & 25 & 50 & 0.42 & $\mathrm{~S}$ & 2 & $\mathrm{I}$ \\
B. cereus & 10876 & 1.69 & 9.3 & 25 & 0.17 & $\mathrm{~S}$ & 2 & $\mathrm{I}$ \\
P. aeruginosa & 9027 & 8.62 & 25 & 50 & 0.69 & $\mathrm{AD}$ & 3.32 & $\mathrm{I}$ \\
L. monocytogenes & 19115 & 4.31 & 10.65 & 10 & 0.75 & $\mathrm{AD}$ & 3 & $\mathrm{I}$ \\
\hline
\end{tabular}

${ }^{2}$ The fractional inhibitory concentration (FIC) index was calculated by the following formula:

$\mathrm{FIC}_{1}=\left(\mathrm{MIC}_{1}\right.$ combined $/ \mathrm{MIC}_{1}$ alone $), \mathrm{FIC}_{2}=\left(\mathrm{MIC}_{2}\right.$ combined $/ \mathrm{MIC}_{2}$ alone $)$

$\mathrm{FIC}=\mathrm{FIC}_{1}+\mathrm{FIC}_{2}$

The results were interpreted as: $\mathrm{FIC} \leq 0.5$ : synergistic activity (S), $0.5<\mathrm{FIC} \leq 1$ : additive activity $(\mathrm{AD}), 1<\mathrm{FIC} \leq 4$ : no interaction (I) and FIC > 4: antagonistic activity was observed.

Table 3. MIC values of lipopeptides extract (LPE) from B. amyloliquefaciens MTCC 10456 against fungal pathogens

\begin{tabular}{lcc}
\hline Fungi & NCIM No. & $\begin{array}{c}\text { MIC of LPE } \\
\left(\mathrm{mg} \mathrm{mL}^{-1}\right)\end{array}$ \\
\hline T. crustaceus & CRS-15 & 0.08 \\
N. hiratsukae & CRS-16 & 0.08 \\
A. fumigatus & 519 & 0.08 \\
R. oryzae & 878 & 0.04 \\
P. funiculosum & $\mathrm{S} 8$ & 0.70 \\
C. albicans & 3100 & 5.62 \\
\hline
\end{tabular}

The mass spectra of fraction 2 showed intense mass peaks at masses 1030.63, 1044.65 and 1058.67 which were attributed to sodium adducts of C13 surfactin, C14 surfactin and C15 surfactin, when compared with published studies $^{25}$. Protonated peaks $[\mathrm{M}+\mathrm{H}]^{+}$were present at $m / z$ values $1008.63,1022.65$ and 1036.67 , which differed by a mass difference of 14 , corresponding to $-\mathrm{CH}_{2}$ group. MS/MS fragmentation of the peak at $\mathrm{m} / \mathrm{z} 1058.67$ showed peaks at $\mathrm{m} / \mathrm{z}$ of 1040,1022 and 1007 with a neutral loss of $\mathrm{H}_{2} \mathrm{O}$ molecule. Ion peaks of $\mathrm{m} / \mathrm{z} 391,945,832,717$ and 618 were 
observed which confirmed the assignment of fraction 2 as C15 surfactin consisting of Glu-leu/ ile-leu-val-asp-leu-leu/ile peptide attached to $\beta$-amino fatty acid chain ${ }^{26}$ (Supplementary data, Fig. S3). Surfactin homologues were observed in fraction 2 responsible for conferring significant antibacterial and antifungal properties, which have been well documented in research reports ${ }^{27,28}$. LC-ESI-MS/MS has been proven to be an efficient technology with high sensitivity, accuracy and require low sample volumes which makes them ideal tools for rapid identification of antimicrobial peptides from diverse microorganisms. Using this technique, many members of Bacillus species have been screened for the production of antimicrobial peptides from their culture medium as well as from the cell pellet.

\section{MIC determination and synergism study}

MIC values of $L P E$ against tested pathogens were determined by micro-broth dilution assay, as shown in Table 2 and 3. When LPE was combined with nisin (3:2 w/w), a significant reduction in MIC values was obtained against bacterial pathogens, as indicated by the FIC values. MIC values of $\mathrm{LPE}+$ Nisin were reduced by $69.5 \%$ against $S$. aureus ATCC $6538,78.8 \%$ against $E$. coli ATCC $35218,74.8 \%$ against $S$. enterica ATCC $12011,90 \%$ against $B$. cereus ATCC $10876,55 \%$ against $L$. monocytogenes ATCC 19115 and $50 \%$ against $P$. aeruginosa ATCC 9027. No interaction was observed between LPE with pediocin. Both, nisin and pediocin did not exhibit antifungal activity against any of the tested pathogens. Thus, synergism was not tested against fungal pathogens. Nisin is the most widely tested bacteriocin in active food packaging against bacterial pathogens and approved by United States Food and drug administration (USFDA). However, its narrow inhibition spectrum and inactivation at alkaline $\mathrm{pH}$ values limits its use for broad variety of packaging systems. Further research with higher concentrations or with combinations of antimicrobials has been suggested by recent reports $^{9}$. In this study, combination of LPE with nisin asserted significant synergistic effect on the tested pathogens. Synergistic antibacterial effect is usually often observed when the two compounds act on different targets, thus increasing their efficacy to attack the host cells. Nisin specifically binds to lipid II in peptidoglycan layer and thus it is only efficient against Gram-positive bacteria, while Gram negative bacteria are protected by the outer membrane which is mainly composed of lipopolysaccharides that are negatively charged. However, when chelating agents e.g. EDTA are used to destabilize the outer membrane, nisin can efficiently inhibit Gramnegative bacteria ${ }^{31}$. Antibacterial mode of action of surfactin includes: binding of divalent cations in the cell membrane causing destabilization, formation of ion channels and insertion into bilipid layer to alter permeability ${ }^{32}$. Thus, a possible explanation of the synergistic effect between surfactin and nisin is that the surfactin affects the cell membrane integrity such that nisin can pass through outer membrane of Gram-negative bacteria. Presence of antifungal bacillomycin D did not affect the synergistic activity and thus usage of mixture of antimicrobials would not only increase the inhibition spectrum but also prevent overuse of one type of antimicrobial compounds, reduce
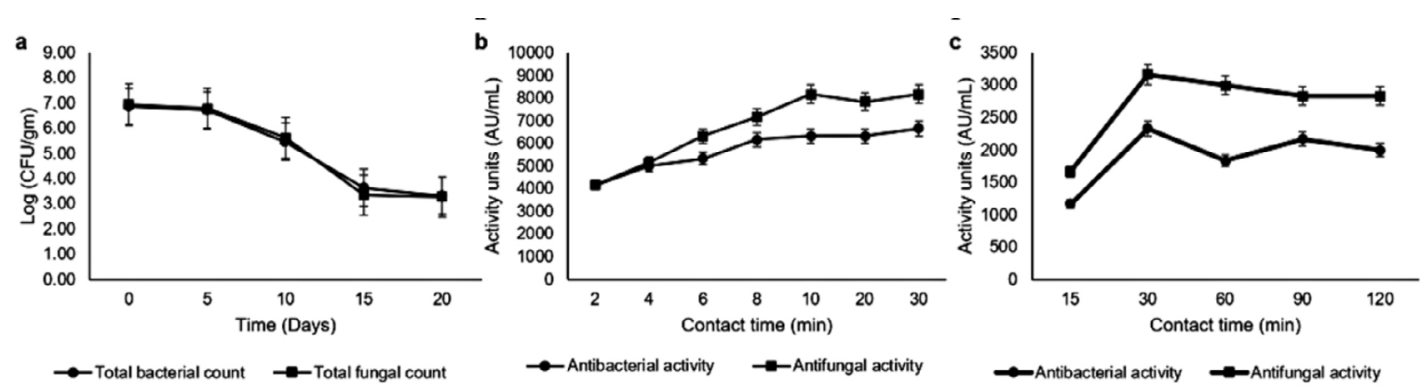

Fig. 5. Evaluation of LPE+Nisin for cardboard preservation a. Reduction in microbial count of treated cardboard $b$. Binding of LPE+Nisin to cardboard surfact at different contact times c. Release of LPE+Nisin from the cardboard surface at different times 
the production cost as well as safety concerns associated with them.

\section{Stability profile}

When LPE was subjected to $\mathrm{pH}$ values from 2 to 10 , the highest antimicrobial activity was observed at pH 6 and 7. Activity was decreased to $80 \%$ and $90 \%$ at $\mathrm{pH} 2$ and 10 , respectively. The antimicrobial activity of LPE was retained in temperature range of $20^{\circ} \mathrm{C}$ to $80^{\circ} \mathrm{C}$. However, activity was decreased to $60 \%$ and $40 \%$, when exposed to $100^{\circ} \mathrm{C}$ and $120^{\circ} \mathrm{C}$ for 30 seconds, respectively. However, antimicrobial activity of LPE was lost after incubating at $121^{\circ} \mathrm{C}$ for 30 min (Supplementary data, Fig. S4). $100 \%$ of antimicrobial activity was retained when LPE was stored at $4^{\circ} \mathrm{C}$ and $-20^{\circ} \mathrm{C}$ for 700 days. Thus, these results indicate long-term stability of LPE which makes them suitable for commercial use. These results are in correlation with those reported by
Chen et al., (2017) $)^{29,}$ and Zhang et al., (2018) which indicate towards the stable nature of antimicrobial peptides produced from Bacillus spp which is required for use in packaged products as they are exposed to different temperature and $\mathrm{pH}$ profiles during handling, storage and distribution. Effect of combination of lipopeptides and nisin on the cardboard spoilage microflora Visual observation and antimicrobial activity of treated cardboard surfaces

Cardboard samples treated with LPE+Nisin were visually observed after every 5 days to check for microbial contamination. In untreated cardboard samples, microbial growth started appearing after 14 days of incubation at $25^{\circ} \mathrm{C}$ and $37^{\circ} \mathrm{C}$ while in plates incubated at $55^{\circ} \mathrm{C}$, microbial growth was observed after 30 days of incubation (Fig. 4). Thus, treated cardboard samples incubated at $25^{\circ} \mathrm{C}$ were used for subsequent experiments to

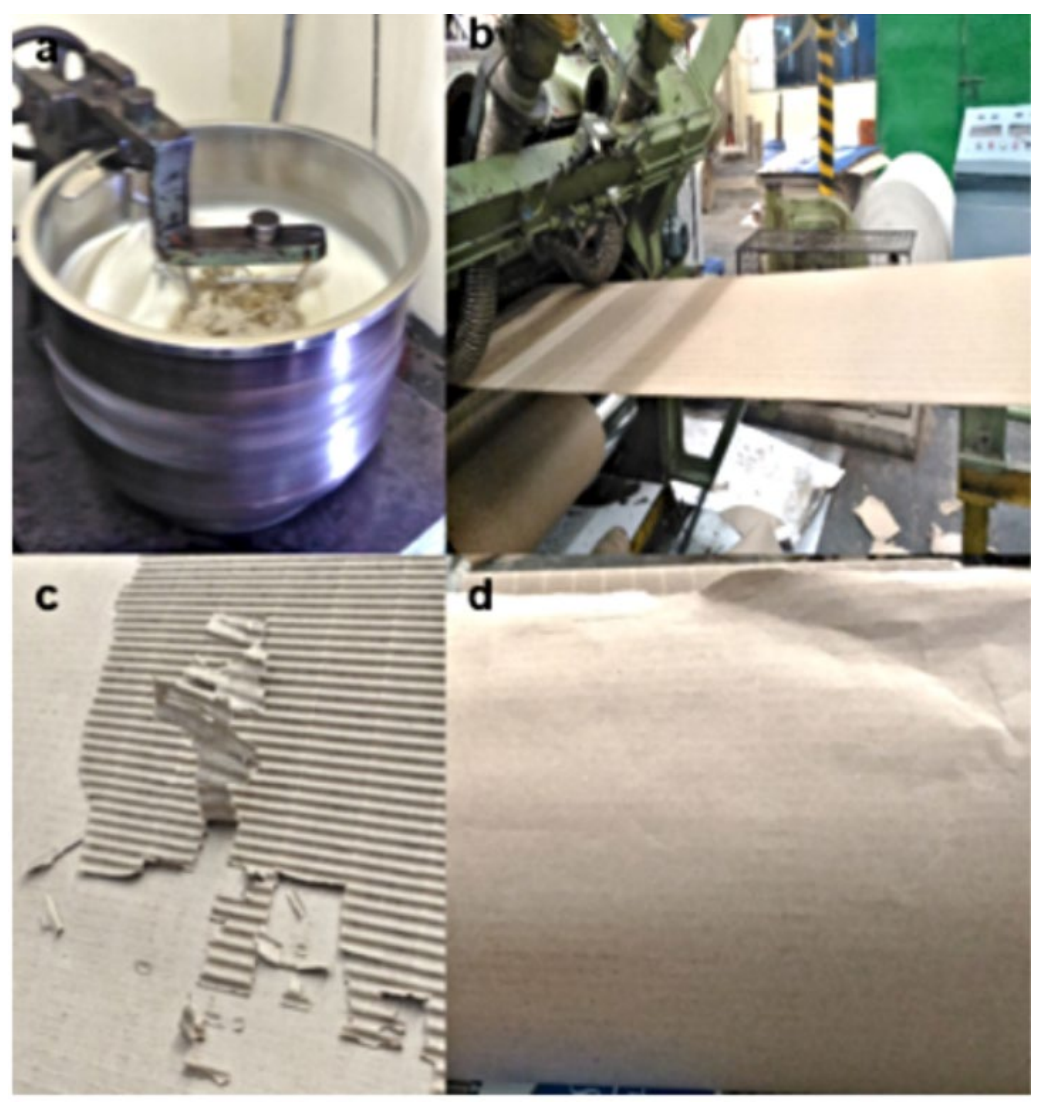

Fig. 6. Factory trial of LPE+Nisin mixture $(0.06 \% \mathrm{w} / \mathrm{w})$ on the cardboard boxes. A. Mixing of starch based glue with $\mathrm{LPE}+\mathrm{Nisin} \mathrm{B}$. Spread coating of LPE+Nisin to corrugated cardboard on a roller tray C. Observation of spoilage free cardboard after 90 days D. Observation of spoilage free cardboad after 180 days 
simulate warehouse conditions. When the treated cardboard samples were tested for antimicrobial activity, clear zone of inhibition was observed around the cardboard surface. It indicated that the LPE+Nisin was uniformly distributed along the surface of the cardboard and retained its activity as observed by Mauriello et al., (2005) ${ }^{14}$. Interestingly, the treated cardboards coated with two different concentrations of LPE+Nisin ( $1 \%$ and $2 \% \mathrm{w} / \mathrm{w}$ ) resisted the growth of microorganisms till 180 days of incubation period. These results are in correlation with study conducted by Lee et al., (2004) $)^{34}$ in which paperboard was coated with nisin for preservation of perishable foods.

\section{Reduction in total microbial count}

An initial microbial load of bacterial and fungal strains isolated from the spoiled cardboard samples $\left(10^{6} \mathrm{CFU} \mathrm{gm}{ }^{-1}\right)$ was added for monitoring accelerated spoilage of cardboard boxes. Reduction in 1 log cycle was observed after 5 days $\left(5 \times 10^{5} \mathrm{CFU} \mathrm{gm}^{-1}\right), 2$ log cycles was observed after 10 days and a decrease in the order of approximately 4 log cycles of microbial population was observed $\left(2 \times 10^{2} \mathrm{CFU} \mathrm{gm}^{-1}\right)$ after 20 days as compared to the untreated cardboard samples in which $10^{9} \mathrm{CFU} \mathrm{gm}{ }^{-1}$ of total microbial population was observed (Fig. 5a). The reduction in the microbial growth can be attributed to the lipopeptides and nisin incorporated in the cardboard samples. These findings reveal that $\mathrm{LPE}+\mathrm{Nisin}$ not only acts as a preservative coating but also contributes in reduction of the existing microbial load in the cardboard samples. These studies are in correlation with other reports of Nithya et al., (2013) ${ }^{22}$ and Mauriello et al., (2005) ${ }^{14}$ for preservation studies using other natural metabolites.

\section{Adsorption and release rates}

When binding of $L P E+N i s i n$ to the cardboard surface was assessed, the treated cardboard samples showed a steady increase in the antimicrobial activity till $6500 \mathrm{AU} \mathrm{mL}^{-1}$ against E. coli ATCC 35218 and $8000 \mathrm{AU} \mathrm{mL}^{-1}$ against $T$. crustaceus CRS-15 up to 10 min after which it remained constant (Fig. 5b). This observation indicated that LPE+Nisin gets adsorbed or absorbed to the cardboard surface in a short period of time and diffuses throughout the surface to form a coating as reported with other bacteriocins ${ }^{14}$. When the release of LPE+Nisin from the cardboard surface was determined, the water samples from 0 to $30 \mathrm{~min}$ showed steady increase in antimicrobial activity after which it remained constant at 2000 AU $\mathrm{mL}^{-1}$ against E. coli ATCC 35218 and $3000 \mathrm{AU}$ $\mathrm{mL}^{-1}$ against $T$. crustaceus CRS-15, till $120 \mathrm{~min}$. When the cardboard samples were tested from 30 to $120 \mathrm{~min}$, they retained constant antimicrobial activity as evidenced by clear zone of inhibition around the indicator strains, implying that the LPE+Nisin was retained in the cardboard surface. These results showed that $\mathrm{LPE}+\mathrm{Nisin}$ released only up to $30 \mathrm{~min}$ of incubation which indicated the suitability of treated cardboards for packaging purposes for an extended period of time (Fig. 5c). The interactions of the antimicrobial agents with the paperboard surface is necessary for the antimicrobial activity of the packaging surfaces. The rapid adsorption and the close alignment of lipopeptides on the cardboard surface may be contributed to its specific amphiphilic structure ${ }^{35}$. The hydrophilic composition of corrugated cardboard makes it likely to adsorb higher amounts of nisin and lipopeptides and greater retention of antimicrobial activity for long-term storage ${ }^{36}$.

\section{Factory trial}

Cardboard samples of size 5 inches $\times 5$ inches were cut from the manufactured boxes and were monitored in the laboratory for microbial spoilage. It was observed that the cardboard boxes treated with concentrations of $1 \%$ and $0.6 \%(\mathrm{w} / \mathrm{w})$ resisted microbial spoilage and retained antimicrobial activity even after 180 days of incubation at $20-25^{\circ} \mathrm{C}$ (Fig. 6). Cardboard boxes treated with $0.4 \%(w / w)$ of $\mathrm{LPE}+\mathrm{Nisin}$ were susceptible to bacterial and fungal growth after 17 weeks which can be attributed to lower concentration of inhibitory peptides necessary to inhibit the microbial growth (Supplementary data, Fig S5). Thus, $0.6 \%(w / w)$ of LPE+Nisin can be used as an acceptable strategy for suppression of microbial growth and preservation of cardboard boxes during prolonged storage.

\section{CONCLUSION}

Seaweed-associated B. amyloliquefaciens MTCC 10456 demonstrated promising inhibitory activity against thermotolerant $T$. crustaceus, $N$. hiratsukae and $B$. subtilis, isolated from spoiled corrugated cardboard boxes made up of recycled 
paper. It could be attributed to the production of lipopeptides such as bacillomycin $D$ and surfactin, which were isolated and identified by RP-HPLC and LC-ESI-MS/MS analysis, respectively. These lipopeptides in synergism with nisin, were successfully demonstrated as a preservative coating on corrugated cardboard boxes for protection against thermotolerant and spoilage microorganisms up to 180 days. This strategy can be implemented without any changes in the existing process flow since this formulation can be mixed with starch-based additive during the manufacturing of cardboard packaging boxes. This study provides an effective and scalable solution for preservation of paper-based packaging materials from microbial damage during storage. Further research can be carried out for physicochemical characterization of cardboard surfaces after application of these metabolites.

\section{SUPPLEMENTARY INFORMATION}

Supplementary information accompanies this article at https://doi.org/10.22207/JPAM.14.4.31

Additional file: Additional Figs. S1 to S5. Additional Table S1

\section{ACKNOWLEDGMENTS}

We would like to thank 'Central instrumentation facility', Savitribai Phule Pune University (SSPU) Maharashtra, India for mass spectrometric analysis of samples. We also thank the Analytical Sciences Team at Praj Matrix R \& D center for RP-HPLC analysis of lipopeptides.

\section{CONFLICT OF INTEREST}

The authors declare that there is no conflict of interest.

\section{AUTHORS' CONTRIBUTION}

YM: Conceptualization; Funding acquisition; Project administration; Resources; Writing - review \& editing; Supervision. UV, RA, ZA: Data curation; Investigation; Methodology. UV: Formal analysis; Validation; Visualization; Roles/ Writing - original draft.

\section{FUNDING}

None.

\section{DATA AVAILABILITY}

All datasets generated or analysed during this study are included in the manuscript and the supplementary files.

\section{ETHICS STATEMENT}

This article does not contain any studies with human participants or animals performed by any of the authors.

\section{REFERENCES}

1. Paper Packaging Market -Growth, Trends, and Forecast (2020-2025).html.

2. Hladikova Z, Kejlova K, Sosnovcova J, et al. Microbial contamination of paper-based food contact materials with different contents of recycled fiber. Czech J Food Sci. 2015;33(4):308-312. doi:10.17221/645/2014-CJFS

3. Flemming $\mathrm{H}-\mathrm{C}$, Meier $\mathrm{M}$, Schild T. Mini-review: microbial problems in paper production. Biofouling. 2013;29(6):683-696. doi:10.1080/08927014.2013.79 8865

4. Irkin R, Esmer OK. Novel food packaging systems with natural antimicrobial agents. J Food Sci Technol. 2015;52(10):6095-6111. doi:10.1007/s13197-0151780-9

5. Harwood CR, Mouillon J-M, Pohl S, Arnau J. Secondary metabolite production and the safety of industrially important members of the Bacillus subtilis group. FEMS Microbiol Rev. 2018;42(6):721-738. doi:10.1093/ femsre/fuy028

6. Caulier S, Nannan C, Gillis A, Licciardi F, Bragard C, Mahillon J. Overview of the Antimicrobial Compounds Produced by Members of the Bacillus subtilis Group. Front Microbiol. 2019;10:302. doi:10.3389/ fmicb.2019.00302

7. Meena KR, Kanwar SS. Lipopeptides as the Antifungal and Antibacterial Agents: Applications in Food Safety and Therapeutics. BioMed Res Int. 2015;2015:1-9. doi:10.1155/2015/473050

8. Khwaldia K, Arab-Tehrany E, Desobry S. Biopolymer Coatings on Paper Packaging Materials. Compr Rev Food Sci F. 2010;9(1):82-91. doi:10.1111/j.15414337.2009.00095.x

9. Malhotra B, Keshwani A, Kharkwal H. Antimicrobial food packaging: potential and pitfalls. Front Microbiol. 2015;6. doi:10.3389/fmicb.2015.00611

10. Guzinska K, Owczarek M, Dymel M. Investigation in the microbiological purity of paper and board packaging intended for contact with food. Fibres Text East Eur. 2012;6B(96):186-190.

11. Ayed HB, Maalej $\mathrm{H}, \mathrm{Hmidet} \mathrm{N}$, Nasri M. Isolation and biochemical characterisation of a bacteriocin-like substance produced by Bacillus amyloliquefaciens An6. J Glob Antimicrob Resist. 2015;3(4):255-261. 
doi:10.1016/j.jgar.2015.07.001

12. Motta AS, Brandelli A. Characterization of an antibacterial peptide produced by Brevibacterium linens.J App/Microbiol. 2002;92(1):63-70. doi:10.1046/ j.1365-2672.2002.01490.x

13. de Castro RD, de Souza TMPA, Bezerra LMD, Ferreira GLS, de Brito Costa EMM, Cavalcanti AL. Antifungal activity and mode of action of thymol and its synergism with nystatin against Candida species involved with infections in the oral cavity: an in vitro study. BMC Complement Altern Med. 2015;15(1):417. doi:10.1186/s12906-015-0947-2

14. Mauriello G, De Luca E, La Storia A, Villani F, Ercolini D. Antimicrobial activity of a nisin-activated plastic film for food packaging. Lett Appl Microbiol. 2005;41(6):464469. doi:10.1111/j.1472-765X.2005.01796.x

15. Alvarez E, Castillo A, Iturrieta I. Fungal peritonitis by Thermoascus crustaceus in a peritoneal dialysis patient from Chile. Rev Iberoam Micol. 2017;34(4):225-228. doi:10.1016/j.riam.2017.01.004

16. Mares M, Moroti-Constantinescu V-R, Voroneanu L, Doroftei F, Covic A, Mederle O-A. Invasive pulmonary infection due to Thermoascus crustaceus in a kidney transplant recipient. Infect Drug Resist. 2019;12:19291934. doi:10.2147/IDR.S209164

17. Oz Y, Kiraz N, Ozkurt S, Soydan M. Colonization of peritoneal catheter with a thermophilic fungus, Thermoascus crustaceus: a case report. Med Mycol. 2010;48(8):1105-1107. doi:10.3109/13693781003793838

18. Guarro J, Kallas EG, Godoy P, et al. Cerebral Aspergillosis Caused by Neosartorya hiratsukae, Brazil. Emerg Infect Dis. 2002;8(9):989-991. doi:10.3201/eid0809.020073

19. Koutroutsos K, Arabatzis M, Bougatsos G, Xanthaki A, Toutouza M, Velegraki A. Neosartorya hiratsukae peritonitis through continuous ambulatory peritoneal dialysis. J Med Microbiol. 2010;59(7):862-865. doi:10.1099/jmm.0.019133-0

20. Shivaprakash MR, Jain N, Gupta S, Baghela A, Gupta A, Chakrabarti A. Allergic fungal rhinosinusitis caused by Neosartorya hiratsukae from India. Med Mycol. 2009;47(3):317-320. doi:10.1080/13693780802562977

21. Singh RP, Reddy CRK. Seaweed-microbial interactions: key functions of seaweed-associated bacteria. FEMS Microbiol Ecol. 2014;88(2):213-230. doi:10.1111/15746941.12297

22. Nithya V, Murthy PSK, Halami PM. Development and application of active films for food packaging using antibacterial peptide of Bacillus licheniformis Me1. J Appl Microbiol. 2013;115(2):475-483. doi:10.1111/ jam.12258

23. Ma Y, Kong Q, Qin C, et al. Identification of lipopeptides in Bacillus megaterium by two-step ultrafiltration and LC-ESI-MS/MS. AMB Expr. 2016;6(1):79. doi:10.1186/ s13568-016-0252-6

24. Gu Q, Yang Y, Yuan Q, et al. Bacillomycin D Produced by Bacillus amyloliquefaciens Is Involved in the Antagonistic Interaction with the Plant-Pathogenic Fungus Fusarium graminearum. Elliot MA, ed.
Appl Environ Microbiol. 2017;83(19):e01075-17. doi:10.1128/AEM.01075-17

25. Yun J-H, Cho D-H, Lee B, Kim H-S, Chang YK. Application of biosurfactant from Bacillus subtilis C9 for controlling cladoceran grazers in algal cultivation systems. Sci Rep. 2018;8(1):5365. doi:10.1038/s41598-018-23535-8

26. Wang $Y$, Zhang $C$, Wu L, et al. Inhibitory Effect of Bacillus Subtilis WL-2 and Its IturinA Lipopeptides against Phytophthora Infestans. Microbiol. 2019. doi:10.1101/751131

27. Hazarika DJ, Goswami G, Gautom T, et al. Lipopeptide mediated biocontrol activity of endophytic Bacillus subtilis against fungal phytopathogens. BMCMicrobiol. 2019;19(1):71. doi:10.1186/s12866-019-1440-8

28. Ndlovu T, Rautenbach M, Vosloo JA, Khan S, Khan W. Characterisation and antimicrobial activity of biosurfactant extracts produced by Bacillus amyloliquefaciens and Pseudomonas aeruginosa isolated from a wastewater treatment plant. $A M B$ Expr. 2017;7(1):108. doi:10.1186/s13568-017-0363-8

29. Chen Y, Liu SA, Mou H, Ma Y, Li M, Hu X. Characterization of Lipopeptide Biosurfactants Produced by Bacillus licheniformis MB01 from Marine Sediments. Front Microbiol. 2017;8:871. doi:10.3389/fmicb.2017.00871

30. Nastro RA, Arguelles-Arias A, Ongena M, et al. Antimicrobial Activity of Bacillus amyloliquefaciens ANT1 Toward Pathogenic Bacteria and Mold: Effects on Biofilm Formation. Probiotics \& Antimicro Prot. 2013;5(4):252-258. doi:10.1007/s12602-013-9143-1

31. Boziaris IS, Adams MR. Effect of chelators and nisin produced in situ on inhibition and inactivation of Gram negatives. Int J Food Microbiol. 1999;53(2-3):105-113. doi:10.1016/S0168-1605(99)00139-7

32. Carrillo C, Teruel JA, Aranda FJ, Ortiz A. Molecular mechanism of membrane permeabilization by the peptide antibiotic surfactin. Biochim Biophys Acta Biomembr. 2003;1611(1-2):91-97. doi:10.1016/S00052736(03)00029-4

33. Zhang $Q X$, Zhang Y, He LL, Ji ZL, Tong YH. Identification of a small antimycotic peptide produced by Bacillus amyloliquefaciens 6256. Pestic Biochem Physiol. 2018;150:78-82. doi:10.1016/j.pestbp.2018.07.006

34. Lee $\mathrm{CH}, \mathrm{An} \mathrm{DS}$, Lee SC, Park HJ, Leea DS. A coating for use as an antimicrobial and antioxidative packaging material incorporating nisin and $\alpha$-tocopherol. J Food Eng. 2004;62(4):323-329. doi:10.1016/S02608774(03)00246-2

35. Liu J-F, Mbadinga S, Yang S-Z, Gu J-D, Mu B-Z. Chemical Structure, Property and Potential Applications of Biosurfactants Produced by Bacillus subtilis in Petroleum Recovery and Spill Mitigation. Int J Mol Sci. 2015;16(3):4814-4837. doi:10.3390/ijms16034814

36. Taboada-Rodriguez A, Garcia-Garcia I, Cava-Roda R, Lopez-Gomez A, Marin-Iniesta F. Hydrophobic properties of cardboard coated with polylactic acid and ethylene scavengers. I Coat Technol Res. 2013;10(5):749-755. doi:10.1007/s11998-013-9493-3 